International Journal of Humanoid Robotics

Vol. 8, No. 4 (2011) 795-798

(C) World Scientific Publishing Company

DOI: $10.1142 /$ S0219843611002691

\title{
Author Index \\ Volume 8 (2011)
}

Achard, C., see Renna, I.

$1(2011) 127$

Akinfiev, T., see Panovko, G.

$1(2011) 13$

Asada, M., see Ishiguro, H.

Balaguer, B. D. and Carpin, S., A Learning Method to Determine How to Approach an Unknown Object to be Grasped

Balaguer, C., see Villagra, J.

Bätz, G., Scheint, M. and Wollherr, D., Toward Dynamic Manipulation for Humanoid Robots: Experiments and Design Aspects

Borovac, B., Nikolić, M. and Raković, M., How to Compensate for the Disturbances that Jeopardize Dynamic Balance of a Humanoid Robot?

Cabico, M., see Kim, M.-S.

Cao, J., Kubota, N., Li, P. and Liu, H., The Visual-Audio Integrated Recognition Method for User Authentication System of Partner Robots Carpin, S., see Balaguer, B. D.

Chan, J., Nejat, G. and Chen, J., Designing Intelligent Socially Assistive Robots as Effective Tools in Cognitive Interventions

Che, D. and Zhang, W., A Dexterous and Self-Adaptive Humanoid Robot Hand: GCUA Hand

Chellali, R., see Renna, I.

Chen, H. and Li, Y., Optimized Particles for $3 D$ Tracking

Chen, J., see Chan, J.

Chen, W., Xiong, C., Sun, R. and Huang, X., A 10-Degree of Freedom Exoskeleton Rehabilitation Robot with Ergonomic Shoulder Actuation Mechanism

Chen, X., see Liu, J.

Chen, Z., Lii N. Y., Wimböck, T., Fan, S. and Liu, H., Experimental Evaluation of Cartesian and Joint Impedance Control with Adaptive Friction Compensation for the Dexterous Robot Hand DLR-HIT II

Chong, C. W., see Low, K. H.

Choo, H., see Lee, K.

Dai, J. S., see Wei, G.

Dillmann, R., see Xue, Z.

Esfahani, E. T. and Sundararajan, V., Using Brain-Computer Interfaces to Detect Human Satisfaction in Human-Robot Interaction

Fan, S., see Chen, Z.

Gasteratos, A., see Nalpantidis, L.

Gong, L., see Kim, M.-S.

Goris, K., Saldien, J., Vanderborght, B. and Lefeber, D., Mechanical Design of the Huggable Robot Probo

Goswami, A., see Kalyanakrishnan, S.

3 (2011) 391

3 (2011) 579

1 (2011) 27

3 (2011) 513

3 (2011) 533

$2(2011) 359$

$4(2011) 691$

3 (2011) 579

$1(2011) 103$

$1(2011) 73$

1 (2011) 127

4 (2011) 631

1 (2011) 103

1 (2011) 47

2 (2011) 323

4 (2011) 649

1 (2011) 185

3 (2011) 607

3 (2011) 459

4 (2011) 761

1 (2011) 87

4 (2011) 649

1 (2011) 169

2 (2011) 359

3 (2011) 481

2 (2011) 245 
Havangi, R., Teshnehlab, M. and Nekoui, M. A., A Novel Adaptive

Neuro-Fuzzy Unscented Kalman Filter for SLAM

$1(2011) 223$

$\mathrm{Hu}, \mathrm{H}$., see Wei, L.

Huang, X., see Chen, W.

Hurst, J. W., The Electric Cable Differential LEG: A Novel Design

$4(2011) 707$

$1(2011) 47$

Approach for Walking and Running

Hwang, J.-H., see Lee, K.

Ishiguro, H., Minato, T., Yoshikawa, Y. and Asada, M., Humanoid Platforms for Cognitive Developmental Robotics

Jiang, X.-Z., Xiong, C.-H., Sun, R.-L. and Xiong, Y.-L., Characteristics of the Robotic Joint of a 9-DoF Upper Limb Rehabilitation Robot Driven by Pneumatic Muscles

Ju, Z., Zhu, X. and Liu, H., Empirical Copula-Based Templates to Recognize Surface EMG Signals of Hand Motions

Kalyanakrishnan, S. and Goswami, A., Learning to Predict Humanoid Fall

Kim, J.-Y. and Kim, Y.-S., Development of Motion Capture System Using Dual Video Cameras for the Gait Design of a Biped Robot

Kim, M.-S., Gong, L., Saito, N., Nishigaya, K., Cabico, M. and LaFontaine, P., The Role of Self-Construal on Preferred Communication Styles with Humanoid Robots

Kim, Y.-S., see Kim, J.-Y.

Kirchner, F., see Lemburg, J.

Kubota, N., see Cao, J.

Kwon, D.-S., see Lee, K.

LaFontaine, P., see Kim, M.-S.

Lee, K., Hwang, J.-H., Kwon, D.-S. and Choo, H., Bring Common Ground into Robotics

Lefeber, D., see Goris, K.

Lemburg, J. and Kirchner, F., Conceptual and Embodiment Design of Robotic Prototypes

Li, P., see Cao, J.

Li, Y., see Chen, H.

Li, Y., see Wang, J.

Lii N. Y. see Chen, Z.

Liu, H., see Cao, J.

Liu, H., see Chen, Z.

Liu, H., see Ju, Z.

Liu, J., Wu, J., Xiong, Z. and Zhu, X., A Relay-Based Approach for Robot Motion Control with Joint Friction and Gravity Compensation

Liu, J., Xue, F. and Chen, X., A Universal Biped Walking Generator for Complex Environments with Pattern Feasibility Checking

Liu, Y., Yang, J. and Wu, Z., Ubiquitous and Cooperative Network Robot System within a Service Framework

Low, K. H., Chong, C. W., Zhou, C. and Seet, G., A Performance Predictive Model for Steady Swimming of a Fish Robot

Luo, H., see Wei, G.

Maufroy, C., see Radkhah, K.

Maus, M., see Radkhah, K.

Midorikawa, Y., see Nakamura, T.

Minato, T., see Ishiguro, H.

2 (2011) 301

3 (2011) 607

3 (2011) 391

$4(2011) 743$

4 (2011) 725

2 (2011) 245

$2(2011) 275$

2 (2011) 359

2 (2011) 275

3 (2011) 419

4 (2011) 691

3 (2011) 607

2 (2011) 359

3 (2011) 607

3 (2011) 481

3 (2011) 419

4 (2011) 691

$4(2011) 631$

4 (2011) 777

4 (2011) 649

4 (2011) 691

4 (2011) 649

4 (2011) 725

4 (2011) 673

2 (2011) 323

1 (2011) 147

1 (2011) 185

3 (2011) 459

3 (2011) 439

3 (2011) 439

1 (2011) 205

3 (2011) 391 
Myalo, E., see Panovko, G.

$1(2011) 13$

Nakamura, T., Midorikawa, Y. and Tomori, H., Position and Vibration Control of Variable Rheological Joints Using Artificial Muscles and Magneto-Rheological Brake

$1(2011) 205$

Nalpantidis, L. and Gasteratos, A., Stereovision-Based Fuzzy Obstacle Avoidance Method

Nejat, G., see Chan, J.

Nekoui, M. A., see Havangi, R.

Nikolić, M., see Borovac, B.

Nishigaya, K., see Kim, M.-S.

Panovko, G., Myalo, E. and Akinfiev, T., Maintenance of Walking Robot in Steady Position by Means of Vibration

Radkhah, K., Maufroy, C., Maus, M., Scholz, D., Seyfarth, A. and von Stryk, O., Concept and Design of the BioBiped1 Robot for Human-Like Walking and Running

Raković, M., see Borovac, B.

Renna, I., Chellali, R. and Achard, C., Real and Simulated Upper Body Tracking with Annealing Particle Filter and Belief Propagation for Human-Robot Interaction

$1(2011) 169$

$1(2011) 103$

$1(2011) 223$

$3(2011) 533$

$2(2011) 359$

$1(2011) 13$

$3(2011) 439$

3 (2011) 533

$1(2011) 127$

$2(2011) 359$

3 (2011) 481

$3(2011) 513$

3 (2011) 439

$1(2011) 185$

$\mathbf{3}(2011) 439$

$1(2011) 47$

$4(2011) 743$

$1(2011) 87$

Sundararajan, V., see Esfahani, E. T.

Tarokh, M. and Wang, M., A Computational Intelligent Approach to Kinematics Problems in Robotics and Computer Animation

Teshnehlab, M., see Havangi, R.

$\mathbf{2}(2011) 375$

$1(2011) 223$

1 (2011) 205

Tsugawa, S., Automated Driving Systems: Common Ground of Automobiles and Robots

$1(2011) 1$

$3(2011) 481$

Vanderborght, B., see Goris, K.

Villagra, J. and Balaguer, C., A Model-Free Approach for Accurate Joint Motion Control in Humanoid Locomotion

1 (2011) 27

$3(2011) 439$

von Stryk, O., see Radkhah, K.

Wang, J. and Li, Y., Manipulation of a Mobile Modular Manipulator Interacting with the Environment with the Assistance of Tactile Sensing Feedback

$4(2011) 777$

$\mathbf{2}(2011) 375$

3 (2011) 459

Wang, S., see Wei, G.

Wei, G., Dai, J. S., Wang, S. and Luo, H., Kinematic Analysis and Prototype of a Metamorphic Anthropomorphic Hand with a

Reconfigurable Palm

$3(2011) 459$

Wei, L., Hu, H. and Zhang, Y., Fusing EMG and Visual Data for

Hands-Free Control of an Intelligent Wheelchair

$4(2011) 707$

$4(2011) 649$

Wimböck, T., see Chen, Z.

3 (2011) 513

Wollherr, D., see Bätz, G. 
Wu, J., see Liu, J.

4 (2011) 673

Wu, Z., see Liu, Y.

Xiong, C., see Chen, W.

Xiong, C.-H., see Jiang, X.-Z.

1 (2011) 147

1 (2011) 47

4 (2011) 743

Xiong, Y.-L., see Jiang, X.-Z.

4 (2011) 743

Xiong, Z., see Liu, J.

4 (2011) 673

Xue, F., see Liu, J.

Xue, Z. and Dillmann, R., Efficient Grasp Planning with Reachability

2 (2011) 323 Analysis

Yang, J., see Liu, Y.

$4(2011) 761$

1 (2011) 147

Yoshikawa, Y., see Ishiguro, H.

3 (2011) 391

Zhang, W., see Che, D.

Zhang, Y., see Wei, L.

1 (2011) 73

Zhou, C., see Low, K. H.

$4(2011) 707$

Zhu, X., see Ju, Z.

1 (2011) 185

Zhu, X., see Liu, J.

$4(2011) 725$

4 (2011) 673 